\title{
Biochar and Arbuscular Mycorrhizal Fungi Play Different Roles in Enabling Maize to Uptake Phosphorus
}

\author{
Mengying $\mathrm{Li}^{1}$ and Liqun Cai ${ }^{1,2, *}$ \\ 1 College of Resources and Environmental Sciences, Gansu Agricultural University, Lanzhou 730070, China; \\ limengying127@163.com \\ 2 Gansu Provincial Key Laboratory of Arid land Crop Science, Gansu Agricultural University, \\ Lanzhou 730070, China \\ * Correspondence: cailq@gsau.edu.cn
}

Citation: Li, M.; Cai, L. Biochar and Arbuscular Mycorrhizal Fungi Play Different Roles in Enabling Maize to Uptake Phosphorus. Sustainability 2021, 13, 3244. https://doi.org/ $10.3390 /$ su13063244

Academic Editor: Zakaria Solaiman

Received: 23 December 2020

Accepted: 28 February 2021

Published: 16 March 2021

Publisher's Note: MDPI stays neutral with regard to jurisdictional claims in published maps and institutional affiliations.

Copyright: (c) 2021 by the authors. Licensee MDPI, Basel, Switzerland. This article is an open access article distributed under the terms and conditions of the Creative Commons Attribution (CC BY) license (https:/ / creativecommons.org/licenses/by/ $4.0 /)$.

\begin{abstract}
The addition of biochar alters soil habitats and has an active effect on the symbiotic relationship between plants and mycorrhizal fungi. However, it is still unclear whether this effect alters the strategy of phosphorus uptake by plants. Therefore, pot experiments were conducted in order to investigate the effects of mycorrhizal colonization and biochar addition on plant growth, phosphorus absorption, and rhizosphere Olsen-P supply in maize under two moisture conditions-60\% field water capacity (FWC) and 40\% FWC. It was found that the addition of biochar increased the colonization rate of arbuscular mycorrhizal fungi (AMF), and all the addition treatments significantly improved maize biomass, peroxidase (POD) activity, chlorophyll content, photosynthetic rate (Pn), plant height, leaf area, shoot phosphorus content, and phosphorus uptake by maize under the two moisture conditions. In addition, biochar had significant effects on root morphology under both water conditions, whereas AMF only showed significant effects under water stress. In contrast, phosphatase activity and microbial activity were higher in the AMF inoculation treatment than in the biochar addition treatment, and the trend was more significant under water stress. Principal component analysis (PCA) showed that root morphology, rhizosphere microbial activity, phosphatase activity, available phosphorus content, and shoot phosphorus content had significant positive correlations. It was concluded that biochar aids plant uptake of phosphorus mainly by regulating root morphology and plant phosphorus content, whereas the large mycelium of AMF enhances microbial activity and phosphatase activity, thereby enabling more efficient phosphorus uptake by maize, especially under conditions of water stress.
\end{abstract}

Keywords: biochar; AMF; phosphorus; root morphology; rhizosphere

\section{Introduction}

Phosphorus is one of the essential elements for plant growth and development, with a vital role in crop production, and phosphorus deficiency has become an important factor limiting present-day agricultural productivity [1]. Soil usually has a relatively high content of organic and inorganic phosphorus, but due to the strong chemical fixation of phosphorus in the soil, less than $1 \%$ of phosphorus can be directly absorbed and utilized by plants [2]. Orthophosphate anions react quickly with cations, such as calcium in alkaline soils or aluminum and iron in acidic soils, to form little soluble deposits that are difficult to be taken up by plants [3-5]. The hydrolysis of organic and inorganic phosphorus that is mediated by soil microorganisms, root mycorrhizal symbiosis, and plant roots ensures the availability of soil phosphorus in the soil biogeochemical cycle [6]. Therefore, the use of sustainable technologies to improve the availability of soil phosphorus is a challenge that needs to be addressed.

Soil microorganisms play an important role in plant phosphorus uptake by promoting root growth or the distribution of phosphorus between inorganic and organic pools [7]. Arbuscular mycorrhizal fungi (AMF) are symbiotic with most terrestrial plants and are 
found on the surface of roots, and in the cortex and around the epidermis of root cells. The hyphae of AMF are thinner than root hairs, so they can extend into soil micropores that plant roots cannot reach, where they access essential plant growth nutrients (mainly nitrates and phosphates), and then transport those nutrients to their host plant in exchange for carbohydrates. Therefore, mycorrhizal symbiosis has a significant impact on the growth and adaptability of plants [8]. Although AMF can significantly improve the availability of phosphorus, their ability to secrete phosphatase and activate organophosphates is relatively weak [9]. Instead, they preferentially use other methods to improve the utilization of phosphorus. First, AMF can rapidly release carbohydrates produced by photosynthesis to the rhizosphere, thereby promoting microbial reproduction, enhancing the secretion of large amounts of phosphatase and the activation of organophosphates, and thus, indirectly increasing plants' ability to absorb phosphorus [10]. Second, AMF can alter the morphology of plant roots in order to promote phosphorus uptake [11]. For example, Zhang et al. [10] found that AMF can expand the absorption area of plant roots by forming a hyphal network, which can then absorb phosphorus from soil pores and transmit it to new host plants.

Biochar is a carbon-rich stable solid product formed by high-temperature pyrolysis of crop straw, livestock and poultry manure, and other biomass waste under anoxic conditions. It has a particularly important role in the recycling of phosphorus [12,13].

Biochar retains large amounts of soluble phosphate, due to the breakdown of the organophosphate chemical bond in wood tissue during pyrolysis [14]. Thus, the soluble phosphate content in the soil can be increased by the addition of biochar. Organophosphate hydrolysis is mediated by extracellular enzymes, and enzyme activity and microbial biomass are the most important determinants of phosphorus mineralization [6]. The microporous structure of biochar and its content of readily oxidizable organic carbon provides a favorable environment for the growth of microorganisms. Masto et al. [15] found that the microbial biomass carbon (MBC) content increased by threefold, and the phosphatase activity increased by $19 \%$ and finally improved the mineralization of phosphorus when biochar had been added to the soil at a rate of $3.5 \mathrm{t} / \mathrm{ha}$ for 20 days. Vassilev et al. [16] reported that the nutrients present in biocharcoal ash stimulated microorganisms to enhance the secretion of dissolved organophosphates. In addition, biochar was found to affect the availability of phosphorus by influencing root growth. Prendergast-Miller [17] found that the addition of biochar increased the root biomass of barley by $29 \%$ and the contact area between the rhizosphere and soil by $14 \%$, thereby increasing the phosphorus uptake of roots by $27 \%$.

The ability of roots to take up nutrients depends on the response of both root morphology (root structure) and root physiological plasticity (e.g., root exudates, nutrient absorption) to the soil environment [10]. For example, low-phosphorus conditions can promote the formation of lupin cluster roots and the secretion of citrate, whereas an increase in phosphorus levels can inhibit this change [18]. Using ${ }^{33} \mathrm{P}$, Hammer et al. [19] confirmed that the hyphae of AMF can extend into the micropores of biochar and thus obtain phosphorus. Several studies have shown that the addition of biochar improves AMF colonization rates [20-22]; the mechanisms responsible for this may include the modification of soil properties and changes in microbial activity [23]. Plants can benefit from interactions between the AMF hyphal network and biochar because these enable otherwise inaccessible nutrient-rich areas to be reached [13]. However, some studies have yielded conflicting findings, and although research has focused considerable attention on the effects of biochar and AMF on plant growth, much less is known about their effects on the access to and the uptake of phosphorus by plants. Therefore, we hypothesized that biochar and AMF might have a synergistic effect to enhance phosphorus uptake by plants. The Loess Plateau belongs to an arid and semi-arid agricultural region, and water resources have been in short supply for a long time. Previous studies have found that AMF can help plants absorb nutrients and have good resistance to drought. Therefore, we hypothesized that AMF might play a different role than biochar in helping plants absorb phosphorus under water stress conditions. To test this hypothesis, the objectives of the 
present study were as follows: (1) to investigate the influence of biochar application and AMF on plant growth; (2) to explore the effects of biochar application on the plant-AMF symbiotic relationship and the phosphorus accumulation by plants; (3) to determine how biochar and AMF affect the utilization of soil phosphorus by plants.

\section{Materials and Methods}

\subsection{Experimental Design}

Pot experiments were conducted under a rainout shelter at the Yuzhong Experiment Station of Lanzhou University, Gansu Province, China ( $35^{\circ} 53^{\prime} \mathrm{N}, 104^{\circ} 06^{\prime} \mathrm{E}$, altitude $\left.1620 \mathrm{~m}\right)$. This site in northwest China has a semi-arid climate, with average long-term evaporation of $1700 \mathrm{~mm}$ and an annual rainfall of $340 \mathrm{~mm}$. The rainout shelter prevented rain from affecting the experiment. To explore the effects of AMF and biochar on phosphorus uptake by plants under normal water and drought conditions, two inoculation treatments, two addition treatments, and two water treatments were included in the study (Table 1). The inoculation treatments were as follows: (1) inoculation with the AMF of Funneliformis mosseae $(+\mathrm{A})$, and $(2)$ non-inoculation with $\mathrm{AMF}(-\mathrm{A})$. The addition treatments were as follows: addition of biochar $(5 \% ;+\mathrm{B})$, and non-addition of biochar $(-\mathrm{B})$. The water treatments were as follows: (1) normal-watered (60\% field water capacity (FWC)), and (2) water-stressed (40\% FWC). In total, eight treatments were designed, and each treatment was replicated nine times and arranged in a complete randomized design.

Table 1. Experimental design and application rates of biochar and arbuscular mycorrhizal fungi (AMF).

\begin{tabular}{|c|c|c|c|c|c|c|}
\hline \multirow{2}{*}{ Treatments } & \multicolumn{4}{|c|}{ Addition or Inoculation } & \multirow{2}{*}{ Biochar (\%) } & \multirow{2}{*}{$\operatorname{AMF}(g)$} \\
\hline & Control & AMF & Bio & Bio + AMF & & \\
\hline $40 \%$ FWC & $-\mathrm{A}-\mathrm{B}$ & $+\mathrm{A}-\mathrm{B}$ & $-A+B$ & $+\mathrm{A}+\mathrm{B}$ & $5 \%$ & $40 \mathrm{~g}$ \\
\hline $60 \%$ FWC & $-\mathrm{A}-\mathrm{B}$ & $+\mathrm{A}-\mathrm{B}$ & $-\mathrm{A}+\mathrm{B}$ & $+\mathrm{A}+\mathrm{B}$ & $5 \%$ & $40 \mathrm{~g}$ \\
\hline
\end{tabular}

\subsection{Plant Materials and Growth Conditions}

Soil samples were collected from low-nutrient soil without covering vegetation at the Yuzhong Experiment Station. The soil used in this experiment belongs to the CalcicCambisols, according to the Food and Agricultural Organization (FAO) classification, and has a silty-loam loess texture with a $\mathrm{pH}$ of 8.3. The biochar used in the experiment was commercial milled charcoal sourced from a local supplier (Golden Future Agriculture Technology Co., Ltd., Dalian, Liaoning, China). The biochar was produced from maize straw through pyrolysis at $500{ }^{\circ} \mathrm{C}$ for $120 \mathrm{~min}$, which can convert $35 \%$ of the biomass to biochar in the form of granular particles. The basic composition of biochar is $53.28 \%$ organic carbon, $1.04 \%$ total nitrogen, $0.26 \%$ phosphorus, and $35.64 \%$ ash. The inoculum of F. mosseae (Nicol. \& Gerd) was commercially provided by the Mycorrhiza Laboratory, Qingdao Agricultural University (Qingdao, China) in 2015. The inoculum of F. mosseae was propagated with Trifolium repens $L$. in sterilized soil in a growth chamber for 4 months. The density of spores in the inocula of F. mosseae was estimated by microscopic examination after wet-sieving and centrifugation. Spore numbers were 50-80 per $10 \mathrm{~g}$ of soil. The inoculum mixture contained spores, hyphae, infected clover root residues, and soil prior to the start of the experiment.

Each pot (with a diameter of $23 \mathrm{~cm}$ and a height of $24 \mathrm{~cm}$ ) contained $7 \mathrm{~kg}$ of a mixture of vermiculite and soil (soil to vermiculite ratio of $2: 1, v / v ; 31.5 \%$ pot capacity) [24]. Then we added $350 \mathrm{~g}$ of biochar to each pot and mixed well. The soil had been autoclaved at a continuous high temperature of $160^{\circ} \mathrm{C}$ for $6 \mathrm{~h}$ to kill any living microbial propagules prior to the start of the experiment. After sterilization, we inoculated F. mosseae ( $20 \mathrm{~g})$ when $40 \%$ and $80 \%$ of each pot of mixed soil were reached, respectively. The nutrient solution containing $7.5 \mathrm{~g}$ of urea and $1.68 \mathrm{~g}$ of $\mathrm{P}_{2} \mathrm{O}_{5}$ was applied to each pot prior to planting. The 
seeds that were used in the study were from a locally grown maize hybrid (Shendan 16). The seeds of maize were sterilized in 5\% sodium hypochlorite for $30 \mathrm{~s}$, washed several times with sterile water, and sown directly into the soil. After seedling emergence, the plants were thinned to one plant per pot. The maize seeds were grown in plastic pots under an open rainout shelter $(50 \mathrm{~m}$ long $\times 24 \mathrm{~m}$ wide $\times 5.7 \mathrm{~m}$ high $)$ that was closed during rain events.

\subsection{Measurements}

Maize plants were grown for 12 weeks. For each treatment, nine pots were divided into three subsamples in order to measure the root morphology, the AMF colonization rate, and soil indicators after 12 weeks of plant growth. An Epson root-scanning system was used to measure the root morphology, and after analysis, the roots were dried and weighed at $60^{\circ} \mathrm{C}$. To measure the AMF colonization rate, the potted plants and soil were removed and carefully cleaned, and the roots were cleaned at $-20^{\circ} \mathrm{C}$ for testing. The fine roots (fresh weight of $0.5 \mathrm{~g}$ ) were separated from the remaining fresh roots and cut into $1 \mathrm{~cm}$ sections. Trypan blue stain was then used to observe the AMF colonization, the measurements were taken using the magnified grid line intersection method, and the percentage root colonization was measured with a compound microscope at 200-400× magnification [25].

Plant height, leaf area, leaf chlorophyll content, and the net photosynthesis rate were measured before harvest. The biomass was determined by drying the plant samples at $105^{\circ} \mathrm{C}$ for $30 \mathrm{~min}$, and then further drying them at $65^{\circ} \mathrm{C}$ until they reached a constant weight. Peroxidase (POD) activity was assayed using the method described by Kwak et al. [26]. Fresh leaves ( $1 \mathrm{~g}$ ) were ground with an amount of phosphorus buffer, and the supernatant was made up to a volume of $100 \mathrm{~mL}$ after centrifuging at $4000 \mathrm{r} / \mathrm{min}$. One unit of peroxidase activity will yield $1 \mathrm{mg}$ of purpurogallin from pyrogallol in $30 \mathrm{~s}$ at $470 \mathrm{~nm}(\triangle \mathrm{A} 470 / \mathrm{min} \cdot \mathrm{gFW})$. The net photosynthesis rate was measured on a second fully expanded leaf at the top of each of the three replicate pots between 08:30 h and 10:30 $\mathrm{h}$, using an LI-6400 portable photosynthesis system (Li-Cor, Lincoln, NE, USA). The leaf chlorophyll content was determined by extraction with $85 \%$ propanol. Using propanol as the control solution, the chloroplast content was measured as the light absorption value of the chloroplast pigment extract at $663 \mathrm{~nm}$ and $645 \mathrm{~nm}$ [27].

The soil $\mathrm{pH}$ was measured using a distilled water to soil ratio of $2.5: 1$, which was thoroughly mixed and stirred, and then allowed to stand for $30 \mathrm{~min}$ prior to measurement with a $\mathrm{pH}$ meter [28]. The soil content of the MBC and the microbial biomass nitrogen (MBN) was determined using the chloroform fumigation extraction method (with $\mathrm{K}_{2} \mathrm{SO}_{4}$ ) [29]. Olsen extractable phosphorus was determined by the sodium bicarbonate method [30]. We combined $5 \mathrm{~g}$ of air-dried soil with a small amount of non-phosphorus activated carbon and $100 \mathrm{~mL}$ of $0.5 \mathrm{~mol} / \mathrm{L} \mathrm{NaHCO}_{3}$ solution, and placed it on a shaker for $30 \mathrm{~min}$. Finally, $5 \mathrm{~mL}$ of molybdenum-antimony were added prior to the colorimetric determination of the Olsen-P value on the meter. Shoot phosphorus was determined spectrophotometrically by the molybdovanadophosphate method at $440 \mathrm{~nm}$ [31]. Soil alkaline phosphatase activity was measured by the p-nitrophenol colorimetric method [32]. We passed $1 \mathrm{~g}$ of fresh soil through a $2 \mathrm{~mm}$ sieve, and $4 \mathrm{~mL}$ of alkaline buffer $(\mathrm{Ph}=11)$ and $1 \mathrm{~mL}$ of pNPP solution $(0.025 \mathrm{~mol} / \mathrm{L})$ were added. The mixture was incubated at $3{ }^{\circ} \mathrm{C}$ for $1 \mathrm{~h}$, and then $1 \mathrm{~mL}$ of calcium chloride and $4 \mathrm{~mL}$ of $\mathrm{NaOH}$ solution $(0.5 \mathrm{~mol} / \mathrm{L})$ were added. After shaking and filtering, phosphatase activity at $400 \mathrm{~nm}$ was measured by spectrophotometry. Phosphatase activity was expressed as $\mathrm{mg} \mathrm{pNPP} \mathrm{kg}{ }^{-1}$ soil $^{-1}$, and all soil data were expressed on an oven-dried $\left(105^{\circ} \mathrm{C}\right)$ basis.

\subsection{Statistical Analysis}

SPSS 22.0 and Origin 9 software were used for data analysis and graph production. All variables were analyzed and compared using one-way analysis of variance (ANOVA) and three-way ANOVA. The differences among all treatments were determined using 
Fisher's least significant difference (LSD) test $(p \leq 0.05)$. Principal component analysis (PCA) was used to examine the relationship between soil quality indicators and root parameters. Pearson's correlation coefficients were applied to test the significance of different treatments.

\section{Results}

\subsection{Biomass and Phosphorus Content of Maize}

The addition of biochar significantly increased the AMF infection rate by $26.1 \%$ under $60 \%$ FWC, and $26.7 \%$ under $40 \%$ FWC (Table 2). Compared with $40 \%$ FWC, with or without the addition of biochar and AMF inoculation under $60 \%$ FWC, maize growth indicators, such as peroxidase activity, chlorophyll content, photosynthetic rate, plant height, leaf area, and shoot biomass, were significantly improved. The treatment involving AMF inoculation significantly improved peroxidase activity, chlorophyll content, photosynthetic rate, plant height, and leaf area compared with the treatment involving the addition of biochar under $40 \%$ FWC. Biochar addition did not lead to any significant differences compared with the control except for the leaf area. When the biochar addition and the AMF inoculation were applied together, maize growth indicators were significantly improved compared with those observed after AMF inoculation alone. For example, shoot biomass under the three treatments $(+\mathrm{A}-\mathrm{B},-\mathrm{A}+\mathrm{B}$, and $+\mathrm{A}+\mathrm{B})$ increased by $17.2 \%, 10.3 \%$, and $26.3 \%$ under $60 \%$ FWC, respectively, compared with the control (Table 2). In addition, at both $60 \%$ FWC and $40 \%$ FWC, phosphorus levels and accumulation in maize shoots showed significant differences across all treatments (Figure 1), and biochar exhibited a stronger effect than AMF. For the three treatments $(+A-B,-A+B$, and $+A+B)$ compared with the control, the phosphorus content increased by $7.3 \%, 12.5 \%$, and $19.7 \%$, respectively, under $40 \%$ FWC, and by $10.7 \%, 21.9 \%$, and $28.1 \%$ under $60 \%$ FWC.
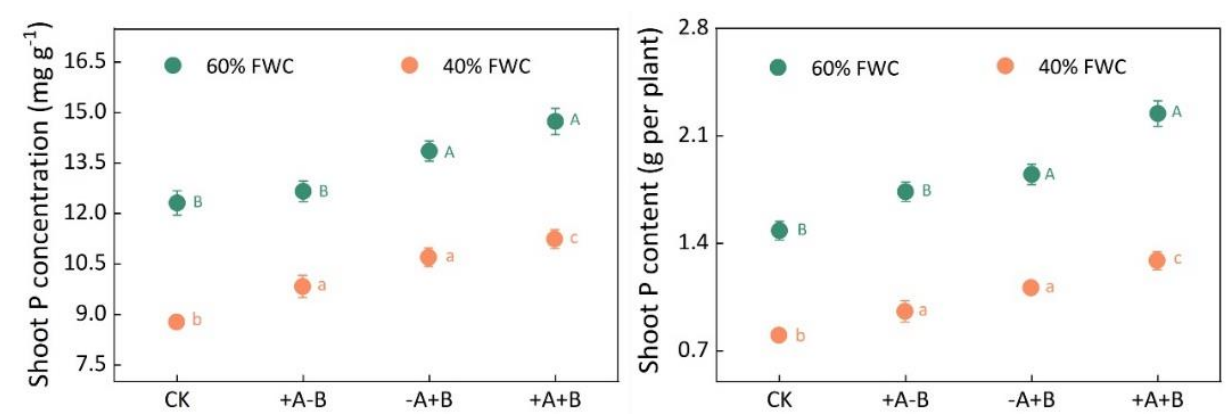

Figure 1. The content and concentration of shoot phosphorus as a function of treatments under different treatment. 
Table 2. Physiology and phenotype of maize in relation to AMF inoculation and biochar addition under $60 \%$ FWC and $40 \%$ FWC.

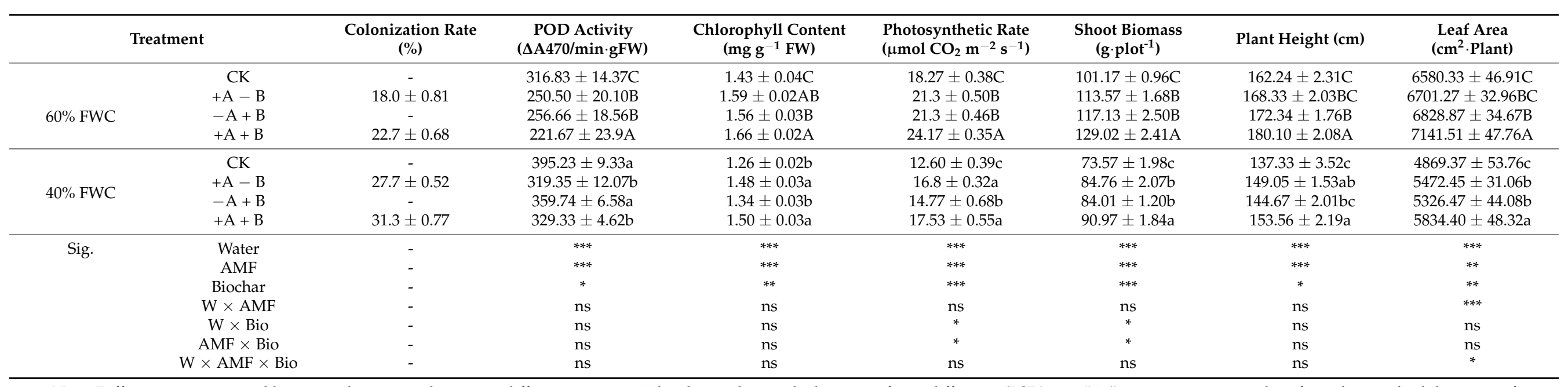

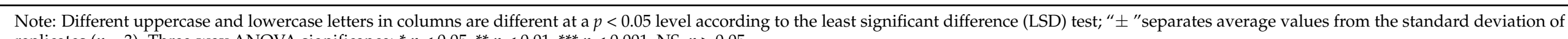
replicates $(n=3)$. Three-way ANOVA significance: ${ }^{*} p<0.05,{ }^{* *} p<0.01,{ }^{* * *} p<0.001, \mathrm{NS}, p>0.05$. 


\subsection{Root Morphological Parameters}

The addition of biochar influenced the morphology of maize root to a significantly greater extent compared with AMF inoculation (Figure 2; Table 3). Under 60\% FWC, the biomass of maize roots increased when both biochar addition and AMF inoculation were applied together. However, the maize root morphology only changed significantly under the treatment involving the biochar addition (Figure 2). That treatment increased the number of root tips, as well as root length, specific root length, root surface area, and root volume under either $40 \%$ FWC or $60 \%$ FWC. When the treatment involving AMF inoculation under $40 \%$ FWC was applied, all of these indicators showed significant increases except for the number of root tips and specific root length. The indicators of maize morphology clearly improved when both the biochar addition and AMF inoculation treatments were applied simultaneously. When the $-\mathrm{A}+\mathrm{B}$ and $+\mathrm{A}+\mathrm{B}$ treatments were applied, the number of root tips increased by $18.6 \%$ and $27.0 \%$, respectively, and the specific root length increased by $26.3 \%$ and $25.0 \%$, respectively, under $60 \%$ FWC. Meanwhile, the three treatments of $+\mathrm{A}-\mathrm{B},-\mathrm{A}+\mathrm{B}$, and $+\mathrm{A}+\mathrm{B}$ respectively increased the root length by $20.9 \%, 54.7 \%$, and $83.5 \%$, and the root biomass increased by $16.6 \%, 16.8 \%$, and $27.9 \%$. The three treatments $+\mathrm{A}-\mathrm{B},-\mathrm{A}+\mathrm{B}$, and $+\mathrm{A}+\mathrm{B}$ increased the root length by $20.9 \%$, $54.7 \%$, and $83.5 \%$, respectively, and increased the root biomass by $16.6 \%, 16.8 \%$, and $27.9 \%$, respectively. The results of the three-way ANOVA show that the water and biochar had significant effects on the maize root morphology. Although the AMF had a significant effect on other root morphological indexes, except for root tip number and specific root length, it can be seen from Figure 2 that the significant effect was mainly caused by water stress.

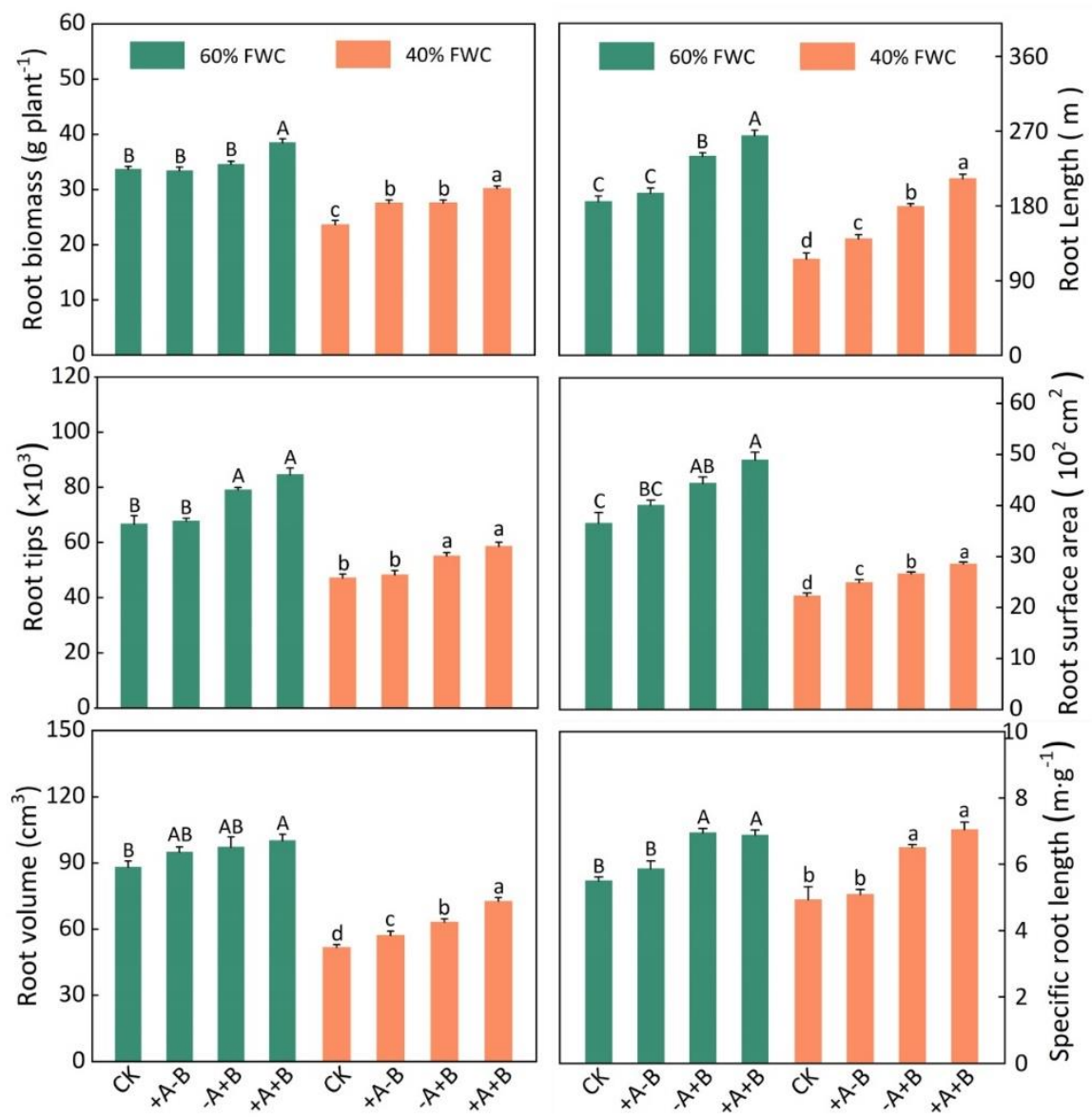

Figure 2. Responses of maize root morphology to AMF inoculation/no inoculation and biochar addition/no addition under two water gradients. 
Table 3. Three-way ANOVA of the effects of water gradients, AMF inoculation, and biochar addition, and their interaction on maize root morphology and rhizosphere biochemical parameters.

\begin{tabular}{|c|c|c|c|c|c|c|c|c|c|c|c|c|c|}
\hline Treatment & RL & RSA & RTN & RB & RV & SRL & Phosp-E & Olsen-P & $\mathrm{pH}$ & MBC & MBN & $\mathrm{C}: \mathrm{N}$ & PC \\
\hline Water & $* * *$ & $* * *$ & $* * *$ & $* * *$ & $* * *$ & $*$ & $* * *$ & $* * *$ & ns & $* * *$ & $* * *$ & ns & $* * *$ \\
\hline AMF & * & * & ns & * & * & ns & $* * *$ & $* * *$ & ns & $* * *$ & $* * *$ & $*$ & $* * *$ \\
\hline Biochar & $* * *$ & $* * *$ & $* * *$ & $* *$ & $* * *$ & $* * *$ & ns & $* * *$ & $* * *$ & $* *$ & $*$ & ns & $* * *$ \\
\hline $\mathrm{W} \times \mathrm{AMF}$ & ns & ns & ns & $*$ & ns & ns & $*$ & $*$ & ns & ns & ns & ns & ns \\
\hline $\mathrm{W} \times$ Bio & $*$ & $*$ & $*$ & ns & ns & ns & ns & ns & ns & $*$ & $* *$ & $*$ & ns \\
\hline $\mathrm{AMF} \times \mathrm{Bio}$ & ns & ns & ns & $*$ & ns & ns & ns & $*$ & ns & ns & ns & ns & ns \\
\hline $\mathrm{W} \times \mathrm{AMF} \times$ Bio & ns & ns & ns & $* *$ & ns & ns & ns & ns & ns & ns & ns & ns & $*$ \\
\hline
\end{tabular}

Note: ${ }^{*} p<0.05,{ }^{* *} p<0.01,{ }^{* * *} p<0.001, \mathrm{NS}, p>0.05$. RL: root length; RSA: root surface area; RTN: root tips number; RB: root biomass; RV: root volume; SRL: specific root length; Phosp-E: alkaline phosphatase; MBC: microbial biomass carbon; MBN: microbial biomass nitrogen; SB: shoot biomass; PC: concentration of phosphorus.

\subsection{Rhizosphere Microbial Activity and Available Phosphorus Content}

Under $60 \%$ FWC, the three treatments $+\mathrm{A}-\mathrm{B},-\mathrm{A}+\mathrm{B}$, and $+\mathrm{A}+\mathrm{B}$ increased microbial biomass carbon (MBC) by $33.3 \%, 20.8 \%$, and $45.1 \%$, respectively, compared with the control, and increased microbial biomass nitrogen (MBN) by $35.4 \%, 27.2 \%$, and $78.7 \%$, respectively (Figure 3). Under $40 \%$ FWC, there was no significant difference between the addition of biochar and the control. However, in the $+\mathrm{A}-\mathrm{B}$ and $+\mathrm{A}+\mathrm{B}$ treatments, $\mathrm{MBC}$ increased by $38.0 \%$ and $65.9 \%$, respectively, and $\mathrm{MBN}$ increased by $56.0 \%$ and $72.3 \%$, respectively. Three-way ANOVA showed that AMF inoculation had a significant effect in comparison to the biochar addition (Table 3). Under $60 \% \mathrm{FWC}$, the MBC to MBN ratio was significantly reduced when the biochar addition and $\mathrm{AMF}$ inoculation were applied together, and under $40 \% \mathrm{FWC}$, the MBC to MBN ratio was decreased in the AMF inoculation treatment. There was a decrease in $\mathrm{pH}$ with all the treatments involving the addition of biochar, whether under $40 \%$ FWC or $60 \%$ FWC. Water treatment and AMF inoculation had significant effects on other indexes except for $\mathrm{pH}$, and there was a significant interaction effect between the water treatment and the biochar addition treatment on microbial activity (Table 3).
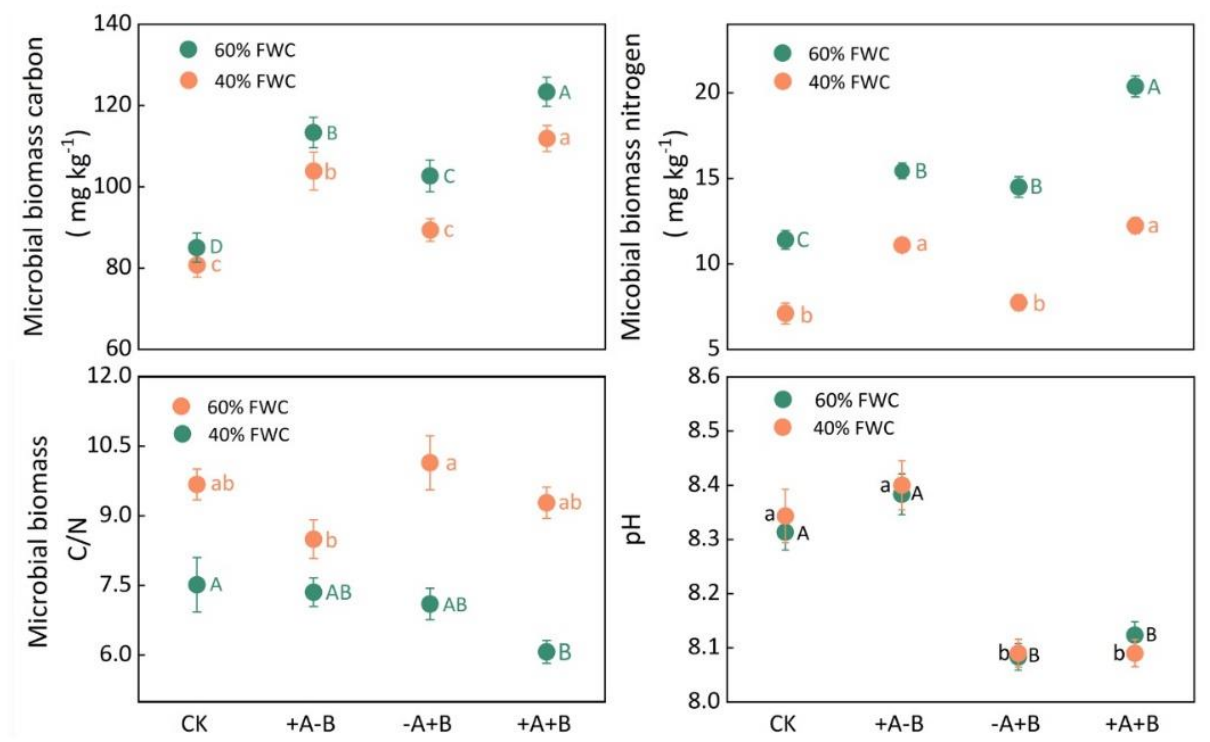

Figure 3. Responses of maize rhizosphere microbial activity and $\mathrm{pH}$ to AMF inoculation/no inoculation and biochar addition/no addition under two water gradients.

The results for the rhizosphere phosphatase activity show that under $60 \% \mathrm{FWC}$, the values for the three treatments $+\mathrm{A}-\mathrm{B},-\mathrm{A}+\mathrm{B}$, and $+\mathrm{A}+\mathrm{B}$ increased by $16.7 \%, 12.6 \%$, and $21.5 \%$, respectively, compared with the control (Figure 4). Under $40 \%$ FWC, only the values for the $+\mathrm{A}-\mathrm{B}$ and $+\mathrm{A}+\mathrm{B}$ treatments increased significantly, by $25.0 \%$ and $40.0 \%$, respectively. 
The content of available phosphorus did not show the same trend as phosphatase activity. With AMF inoculation, biochar addition, or both, the Olsen-P content was significantly increased by $8.4 \%, 20.2 \%$, and $22.5 \%$, respectively, in the $+\mathrm{A}-\mathrm{B},-\mathrm{A}+\mathrm{B}$, and $+\mathrm{A}+\mathrm{B}$ treatments under $60 \%$ FWC, and by $20.6 \%, 35.6 \%$, and $41.4 \%$, respectively, under $40 \%$ FWC.
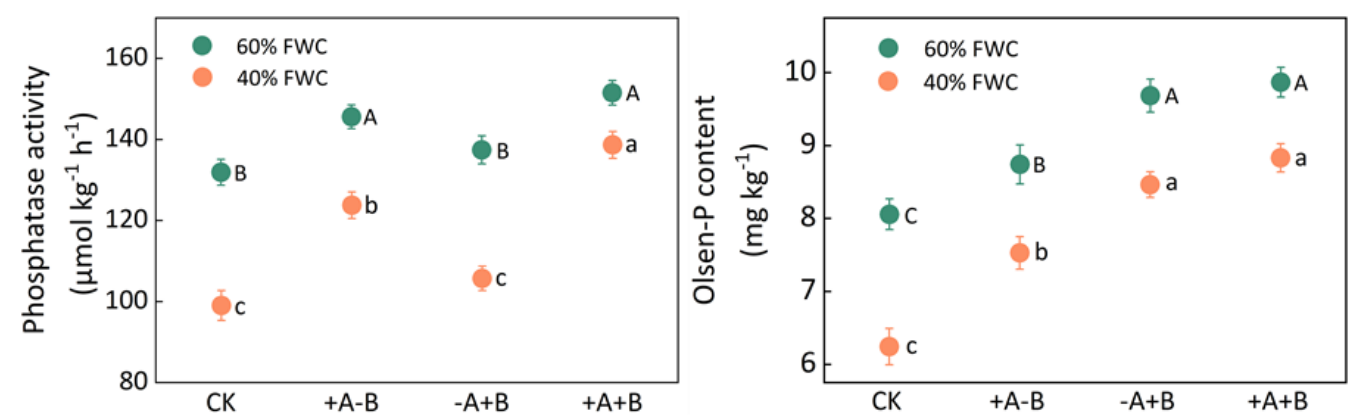

Figure 4. Responses of alkaline phosphatase activity and Olsen-P content of rhizosphere soil to AMF inoculation/no inoculation and biochar addition/no addition under two water gradients.

\subsection{Principal Component Analysis}

PCA (Figure 5; Table 4) showed that the root system indicators (root weight, root surface area, root length, root tip number, specific root length, and root volume) and the rhizosphere microbial indicators ( $\mathrm{MBC}$ and $\mathrm{MBN}$ ) were very significantly correlated with the phosphorus metabolism indicators (phosphatase activity, available phosphorus content, and above-ground phosphorus content). Moreover, under 40\% FWC and 60\% FWC, the PCA had a higher total interpretation degree, of $80.5 \%$ and $84.5 \%$, respectively, and the $+\mathrm{A}+\mathrm{B}$ treatment showed the strongest correlation with the above-mentioned indicators. Combining the results of the PCA and the three-way ANOVA (Table 2) indicate that the biochar addition had a significant effect on the root morphological indicators than did AMF inoculation, whereas the latter had a more significant effect on microbial activity and phosphatase activity than did the biochar addition. In particular, the AMF inoculation amplified the rhizosphere effect under low water conditions, whereas the biochar addition reduced the rhizosphere effect. This demonstrates that biochar and AMF may have different effects on plant phosphorus uptake strategies under different water conditions.
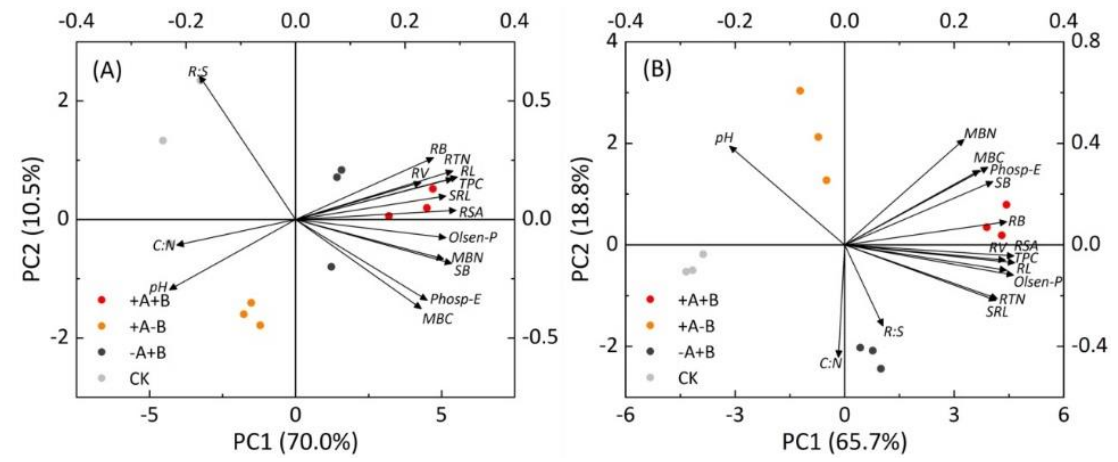

Figure 5. Principal component analysis of the AMF inoculation/no inoculation and biochar addition/no addition under two water gradients of $60 \%$ field water capacity (FWC) (A) and 40\% FWC (B). Arrow length indicates the loading of each trait onto principal component analysis (PCA) axes. Symbols represent the position of treatments along the PCA 1 and 2. MBC: microbial biomass carbon; MBN: microbial biomass nitrogen; RL: root length; RSA: root surface area; RV: root volume; RTN: Root tip number; SRL: specific root length; RB: root biomass; SB: shoot biomass; TPC: phosphorus content. 
Table 4. Pearson correlation coefficients of the effects of AMF inoculation, biochar addition, and their interaction on maize root morphology and rhizosphere biochemical parameters.

\begin{tabular}{|c|c|c|c|c|c|c|c|c|c|c|c|c|c|c|}
\hline & RL & RSA & RTN & RB & RV & SRL & Phosp-E & Olsen-P & $\mathrm{pH}$ & MBC & MBN & C:N & SB & PC \\
\hline $\begin{array}{c}\text { RL } \\
\text { RSA } \\
\text { RTN } \\
\text { RB } \\
\text { RV } \\
\text { SRL } \\
\text { Phosp-E } \\
\text { Olsen-P } \\
\text { pH } \\
\text { MBC } \\
\text { MBN } \\
\text { C:N } \\
\text { SB } \\
\text { TPC }\end{array}$ & 1 & $\begin{array}{c}0.939 * * \\
1\end{array}$ & $\begin{array}{c}0.929 \text { ** } \\
0.919^{* *} \\
1\end{array}$ & $\begin{array}{c}0.839^{* *} \\
0.843^{* *} \\
0.848^{* *} \\
1\end{array}$ & $\begin{array}{c}0.831^{* *} \\
0.840^{* *} \\
0.823^{* *} \\
0.660^{*} \\
1\end{array}$ & $\begin{array}{c}0.935^{* *} \\
0.845^{* *} \\
0.832^{* *} \\
0.593^{*} \\
0.806^{* *} \\
1\end{array}$ & $\begin{array}{c}0.665^{*} \\
0.667^{*} \\
0.600^{*} \\
0.362 \\
0.776^{* *} \\
0.746^{* *} \\
1\end{array}$ & $\begin{array}{c}0.816^{* *} \\
0.751^{* *} \\
0.809^{* *} \\
0.578^{* *} \\
0.822^{* *} \\
0.830^{* *} \\
0.882^{* *} \\
1\end{array}$ & $\begin{array}{c}-0.808^{* *} \\
-0.647^{*} \\
-0.786^{* *} \\
-0.582^{*} \\
-0.564 \\
-0.819^{* *} \\
-0.642^{*} \\
-0.816^{* *} \\
1\end{array}$ & $\begin{array}{c}0.583^{*} \\
0.681^{*} \\
0.542 \\
0.600^{*} \\
0.800^{* *} \\
0.476 \\
0.719^{* *} \\
0.592^{*} \\
0.293 \\
1\end{array}$ & $\begin{array}{c}0.765^{* *} \\
0.811^{* *} \\
0.733^{* *} \\
0.761^{* *} \\
0.905^{* *} \\
0.636^{*} \\
0.634^{*} \\
0.710^{* *} \\
0.413 \\
0.861^{* *} \\
1^{* *}\end{array}$ & $\begin{array}{c}-0.681^{*} \\
-0.686^{*} \\
-0.707^{*} \\
-0.614^{*} \\
-0.733^{* *} \\
-0.608^{*} \\
-0.3 \\
-0.557 \\
0.351 \\
-0.368 \\
-0.776^{* *} \\
1\end{array}$ & $\begin{array}{c}0.829^{* *} \\
0.912^{* *} \\
0.825^{* *} \\
0.792^{* *} \\
0.863^{* *} \\
0.713^{* *} \\
0.715^{* *} \\
0.779^{* *} \\
-0.511 \\
0.819^{* *} \\
0.892^{* *} \\
-0.649^{*} \\
1\end{array}$ & $\begin{array}{c}0.927^{* *} \\
0.829^{* *} \\
0.907^{* *} \\
0.817^{* *} \\
0.853^{* *} \\
0.841^{* *} \\
0.685^{*} \\
0.873^{* *} \\
-0.810^{* *} \\
0.619^{*} \\
0.774^{* *} \\
-0.633^{*} \\
0.773^{* *} \\
1\end{array}$ \\
\hline
\end{tabular}

Note: ${ }^{*} p<0.05,{ }^{* *} p<0.01$, NS, $p>0.05$. RL: root length; RSA: root surface area; RTN: root tips number; RB: root biomass; RV: root volume; SRL: specific root length; Phosp-E: alkaline phosphatase; MBC: microbial biomass carbon; MBN: microbial biomass nitrogen; SB: shoot biomass; PC: concentration of phosphorus.

\section{Discussion}

\subsection{The Effect of AMF and Biochar on Maize Growth and Phosphorus Acquisition}

The growth and metabolic activity of plants is determined both by the plant's photosynthetic capacity and by its ability to utilize soil nutrients. The addition of biochar and the presence of AMF can alter the metabolic environment of plants by affecting the levels of available nutrients in the ground, thereby enhancing the ability of plants to absorb and assimilate $\mathrm{CO}_{2}$ from the atmosphere. Previous studies showed that AMF significantly improved antioxidant enzyme activity, net photosynthetic rate, and above-ground biomass [33]. Many previous studies found that AMF inoculation under drought stress significantly increased dry biomass [34,35]. The present study demonstrates that AMF inoculation reduces peroxidase activity, and increases chlorophyll content, photosynthetic rate, and above-ground biomass. One possible mechanism relates to the ability of AMF hyphae to increase water and nutrient uptake by plants as a result of the symbiotic relationship between plants and AMF [36]. In particular, mycorrhiza can absorb and transport large amounts of nutrients, such as phosphorus, thus improving plant resistance to stressful environments [37]. In addition, the addition of biochar increased peroxidase activity, the photosynthetic rate, above-ground biomass, plant height, and leaf area. Jeffery et al. [38] showed that biochar addition improved average crop productivity by up to $10 \%$, and total organic carbon and nitrogen contents were increased by the addition of a biochar compost mixture to the soil, leading to an increase in biomass, plant height, and grain weight in oats.

Although biochar and AMF both improved the growth performance of maize, they acted in different ways. Biochar improves the physical and chemical properties of soil. For example, it increases both the water holding and cation exchange capacities, thereby optimizing the retention and availability of nutrients. In addition, the growth and stress tolerance of crops are improved when biochar is applied to the soil. As in previous studies, the biochar addition and AMF inoculation increased the phosphorus content of maize shoots, which was attributed to the symbiotic plant-AMF relationship increasing the absorption of phosphorus by plant roots or AMF hyphae [39,40]. Figueiredo et al. [41] found that the addition of biochar significantly increased the colonization rate of AMF and synergically increased the phosphorus absorption. In addition, AMF hyphae increase the surface area available for the absorption of phosphorus, and release exudates that mineralize and solubilize phosphorus [42]. As phosphorus cannot volatilize at temperatures below $500-700{ }^{\circ} \mathrm{C}$, the low pyrolysis temperature of biochar is unlikely to volatilize $\mathrm{P}$ in plant tissues [43]. By comparing the phosphorus content in biochar at different pyrolysis temperatures, Adhikari et al. [43] found that when the pyrolysis temperature reached 500 ${ }^{\circ} \mathrm{C}$, the phosphorus content rose sharply. However, Figueiredo et al. [44] study found that pyrolysis temperature did not affect the phosphorus content of biochar. During pyrolysis the organophosphate bonds within the woody tissue of biomass will be cleaved, releasing soluble forms of phosphorus that remain in the biochar. When biochar is applied to the soil, it also increases the soluble phosphorus content of the soil, enabling plants to absorb 
more phosphorus [31]. The biochar used in this experiment had a pyrolysis temperature of $500^{\circ} \mathrm{C}$ and a high original phosphorus content, which led to a significant increase in plant phosphorus content. In addition, compared with control treatment (CK), the addition of AMF alone only increased the phosphorus content of maize under water stress, while the addition of AMF together with biochar significantly increased the phosphorus content of maize under two water gradients. The three-way ANOVA results also show that the interaction between biochar and AMF was only significant under water stress. The results show that soil moisture content significantly affected the response of plant phosphorus uptake to biochar and AMF. Biochar supplementation significantly increased phosphorus uptake under two water gradients, while AMF had a significant effect only under drought conditions (Figure 6).

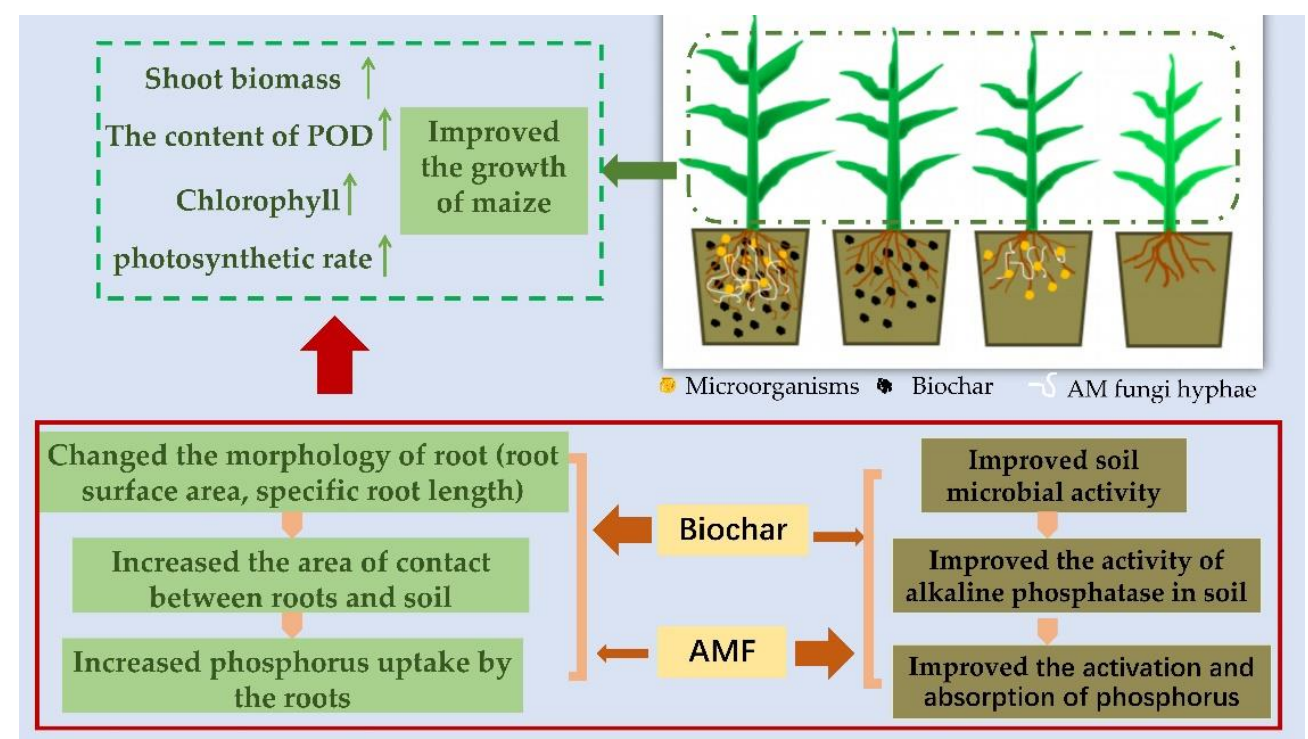

Figure 6. Graphical abstract shows that biochar and arbuscular mycorrhizal fungi play different roles in enabling maize to activate and absorb phosphorus.

\subsection{Effects of AMF and Biochar on the Morphology of the Maize Root System}

The "hunting capacity" of roots plays a key role in plant utilization of underground water and nutrients, which is also dependent on root architecture (morphology) and physiological plasticity [10]. The study found that when tomato seedlings with dampingoff disease were inoculated with AMF, the total root length and the number of root tips increased, which, to some extent, made the plants more resistant to disease [45]. Bi et al. [46] found that AMF can alleviate root damage stress by changing the root morphology. In the present experiment, the morphology of the root system did not change under $60 \%$ FWC, whereas it did change, and the root length, root volume, root surface area, and root weight increased significantly, under $40 \%$ FWC (Figure 2). It is possible that this finding was due to AMF being much less reliant on maize because sufficient water was available. In general, root morphology is not directly affected by AMF inoculation. For example, Cosme et al. [11] found that AMF inoculation alone did not induce a change in root morphology, whereas a significant change in the morphology of the roots occurred in response to the application of appropriate levels of phosphorus. In addition, AMF acting on the root system do not directly cause morphological changes, but mainly affect root hair length and root hair density [47]. Therefore, under $40 \%$ FWC, the observed changes in root morphology may be due to the fact that plants obtain phosphorus and water through AMF to support plant growth and development under low water conditions. Several studies have demonstrated that biochar addition can increase the growth of crop roots [6]. Ameloot et al. [17] reported that the addition of biochar increased the root biomass of spring barley by $29 \%$, and that it increased contact between the rhizosphere and soil by $14 \%$, so that root 
uptake of phosphorus increased by $27 \%$. A study by Zhang et al. [48] found that biochar addition increased the taproot length, the root volume, and the total root absorption area in tobacco.

In the present study, the biochar addition significantly altered the root morphology under both $40 \%$ FWC and 60\% FWC (Figure 2). There are two possible reasons for this. First, biochar can alter the soil environment (by improving soil porosity, cation exchange capacity, etc.), thereby optimizing the root growth space and inducing root extension. Second, biochar contains many nutrients that are utilized by plants. After using computed tomography to visualize the root system, and building a model to simulate the process of citric acid secretion, Daniel et al. [49] concluded that the root surface area has a dominant role in the absorption of phosphorus, and that the number of root tips is increased in order to enhance the secretion of citric acid, thereby increasing the concentration of phosphorus available to plants. Honvault et al. [50] pointed out that the root systems of crops have evolved to allow more efficient "nutrient capture" (especially specific root length) in response to limited phosphorus availability. In the present study, it was found that the plant root morphology was closely related to phosphorus uptake (Figure 5; Table 4). However, the response of the root morphology to the addition of biochar and AMF was different. Biochar supplementation alone significantly affected the maize root morphology under both water gradients, while AMF supplementation alone only significantly affected the maize root morphology under water stress. The results show that under drought conditions, plants depend on AMF to obtain more phosphorus and water, thus indirectly affecting the plant root morphology, while the addition of biochar changes the soil's physical environment, directly causing the change of the plant root morphology.

\subsection{The Effect of AMF and Biochar on Maize Growth and Phosphorus Uptake}

Soil microorganisms can improve the phosphorus nutrition of plants by enhancing root growth (hormonal stimulation), expanding the zone of exploration for phosphorus in the soil (mycorrhizal association), or facilitating organic phosphorus mineralization and inorganic phosphorus dissolution [7]. Although AMF have a weak ability to secrete phosphorus-metabolizing enzymes [9], they can help plants to quickly transfer their fixed carbohydrates to the wider rhizosphere environment, thereby stimulating the growth of rhizosphere microorganisms. In particular, under conditions of phosphorus deficiency, the growth of phosphate-solubilizing bacteria is stimulated [10]. Biochar has a highly stable molecular structure (including a highly concentrated aromatic structure). During the pyrolysis and carbonization of organic matter, about $3 \%$ of unstable carbon sources (aliphatic carbon/carboxyl groups/carbohydrates) accompanied by biochar enter the soil, where they stimulate the growth of microorganisms within a short period of time, resulting in the production of a specific type of microbial community [51]. The present study found that under $60 \%$ FWC, AMF inoculation together with biochar application significantly improved soil microbial activity in the maize rhizosphere, whereas under $40 \%$ FWC, the addition of biochar alone did not increase soil microbial activity. Furthermore, when biochar alone was added under either $40 \%$ FWC or $60 \%$ FWC, phosphatase activity did not differ significantly from that of the control (Figures 3 and 4). This is mainly because, under water stress, the mobility of nutrients and the root input of plants decreased, resulting in the decrease of microbial proliferation ability. Although the addition of biochar optimizes the growth environment of soil microorganisms, this effect is far smaller than the positive effect of AMF inoculation (Table 3). The microbial activity showed significant differences under $60 \%$ FWC, but there was no significant difference in phosphatase activity (Figure 3), whereas under $40 \%$ FWC, the growth of microorganisms was restricted, and phosphatase activity was reduced (Figure 4). In addition, biochar contains large amounts of phosphorus that can be used by plants, so it is possible that plants and microorganisms do not need to secrete much more phosphatase in order to activate phosphorus. The Olsen-P content and microbial phosphatase activity were highest for the $+\mathrm{A}+\mathrm{B}$ treatment, which indicates that biochar improved AMF inoculation. In addition, the effect of AMF on phosphorus 
activation under conditions of water stress needs to be emphasized. Whether or not the addition of biochar increases soil-available phosphorus levels, AMF are more effective in enabling plants to activate and obtain nutrients under stress conditions, and the addition of biochar is not only conducive to AMF growth but could also enable plants to obtain phosphorus from the biochar micropores. These results suggest that AMF inoculation can improve soil microbial biomass, and collaboration with biochar is more conducive to microbial proliferation. On the other hand, under drought stress, plants can strengthen the association with AMF, secrete more organic matter, promote microbial proliferation, and thus improve the activation and absorption of phosphate. However, as a phosphate pool that can be directly used by plants, biochar addition reduced the secretion of microbial phosphatase.

\section{Conclusions}

The graphic abstract presents the main results of this research (Figure 6). The present study confirmed the different effects of AMF inoculation and biochar addition on plant strategies for obtaining phosphorus under conditions of drought stress or normal water availability. Biochar optimized the symbiotic relationship between plants and AMF and improved the AMF inoculation rate. This phenomenon is closely related to the function of improving plant growth performance (both physiology and phenotype). Under two water gradients, biochar addition can change the morphological structure of the root system in maize, thereby enabling the plant to utilize soil phosphorus, more efficiently. It is noteworthy that AMF can only alter the root morphology of plants under drought conditions, but can significantly increase rhizosphere microbial activity, phosphatase activity, and available phosphorus content under both $40 \%$ FWC and $60 \%$ FWC, thus enabling plants to activate and absorb larger amounts of phosphorus. Our results show that biochar and AMF play different roles in the process of phosphorus acquisition by plants, and that a combination of biochar addition and AMF inoculation yields higher rates of phosphorus uptake by plants. This has important implications for optimizing plant strategies for phosphorus uptake, and for the efficient utilization of phosphorus.

Author Contributions: Specifically, M.L. and L.C. were responsible for experimental design. M.L. is also responsible for the original draft preparation. All authors have read and agreed to the published version of the manuscript.

Funding: This work is financially supported by the National Natural Science Foundation of China (Number: 41661049; Host by Li-Qun Cai).

Acknowledgments: We would like to thank Xiong's valuable advice. In addition, we show sincere gratitude to the anonymous reviewers for their valuable comments and suggestions.

Conflicts of Interest: The authors declare no known competing financial interests or any personal relationships that could influence the work reported in this manuscript.

\section{References}

1. Efthymiou, A.; Grønlund, M.; Müller-Stöver, D.S.; Jakobsen, I. Augmentation of the phosphorus fertilizer value of biochar by inoculation of wheat with selected Penicillium strains. Soil Biol. Biochem. 2018, 116, 139-147. [CrossRef]

2. Shen, S.M. On our phosphorus fertilizer production and countermeasures. Chin. J. Soil Sci. 1985, 3, 97-103.

3. Hauggaard-Nielsen, H.; Ambus, P.; Jensen, E.S. Temporal and spatial distribution of roots and competition for nitrogen in pea-barley intercrops-A field study employing 32p technique. Plant Soil. 2001. [CrossRef]

4. Latati, M.; Bargaz, A.; Belarbi, B.; Lazali, M.; Benlahrech, S.; Tellah, S.; Kaci, G.; Drevon, J.J.; Ounane, S.M. The intercropping common bean with maize improves the rhizobial efficiency, resource use and grain yield under low phosphorus availability. Eur. J. Agron. 2016, 72, 80-90. [CrossRef]

5. Grant, C.A.; Flaten, D.N.; Tomasiewicz, D.J.; Sheppard, S.C. The importance of early season phosphorus nutrition. Can. J. Plant Sci. 2001, 81, 211-224. [CrossRef]

6. Gul, S.; Whalen, J.K. Biochemical cycling of nitrogen and phosphorus in biochar-amended soils. Soil Biol. Biochem. 2016, 103, 1-15. [CrossRef]

7. Richardson, A.E. Prospects for using soil microorganisms to improve the acquisition of phosphorus by plants. Aust. J. Plant Physiol. 2001, 28, 897-906. [CrossRef] 
8. $\quad$ van der Heijden, M.G.A.; Martin, F.M.; Selosse, M.A.; Sanders, I.R. Mycorrhizal ecology and evolution: The past, the present, and the future. New Phytol. 2015, 205, 1406-1423. [CrossRef] [PubMed]

9. Tisserant, E.; Malbreil, M.; Kuo, A.; Kohler, A.; Symeonidi, A.; Balestrini, R.; Charron, P.; Duensing, N.; Frei Dit Frey, N.; Gianinazzi-Pearson, V.; et al. Genome of an arbuscular mycorrhizal fungus provides insight into the oldest plant symbiosis. Proc. Natl. Acad. Sci. USA 2013. [CrossRef]

10. Zhang, L.; Xu, M.; Liu, Y.; Zhang, F.; Hodge, A.; Feng, G. Carbon and phosphorus exchange may enable cooperation between an arbuscular mycorrhizal fungus and a phosphate-solubilizing bacterium. New Phytol. 2016, 210, 1022-1032. [CrossRef]

11. Cosme, M.; Wurst, S. Interactions between arbuscular mycorrhizal fungi, rhizobacteria, soil phosphorus and plant cytokinin deficiency change the root morphology, yield and quality of tobacco. Soil Biol. Biochem. 2013, 57, 436-443. [CrossRef]

12. Efthymiou, A.; Jensen, B.; Jakobsen, I. The roles of mycorrhiza and Penicillium inoculants in phosphorus uptake by biocharamended wheat. Soil Biol. Biochem. 2018, 127, 168-177. [CrossRef]

13. Zwetsloot, M.J.; Lehmann, J.; Bauerle, T.; Vanek, S.; Hestrin, R.; Nigussie, A. Phosphorus availability from bone char in a P-fixing soil influenced by root-mycorrhizae-biochar interactions. Plant Soil 2016, 408, 95-105. [CrossRef]

14. Gundale, M.J.; DeLuca, T.H. Temperature and source material influence ecological attributes of ponderosa pine and Douglas-fir charcoal. For. Ecol. Manag. 2006. [CrossRef]

15. Masto, R.E.; Kumar, S.; Rout, T.K.; Sarkar, P.; George, J.; Ram, L.C. Biochar from water hyacinth (Eichornia crassipes) and its impact on soil biological activity. Catena 2013, 111, 64-71. [CrossRef]

16. Vassilev, N.; Martos, E.; Mendes, G.; Martos, V.; Vassileva, M. Biochar of animal origin: A sustainable solution to the global problem of high-grade rock phosphate scarcity? J. Sci. Food Agric. 2013, 93, 1799-1804. [CrossRef]

17. Ameloot, N.; Sleutel, S.; Case, S.D.C.; Alberti, G.; McNamara, N.P.; Zavalloni, C.; Vervisch, B.; delle Vedove, G.; De Neve, S. C mineralization and microbial activity in four biochar field experiments several years after incorporation. Soil Biol. Biochem. 2014, 78, 195-203. [CrossRef]

18. Lambers, H.; Shane, M.W.; Cramer, M.D.; Pearse, S.J.; Veneklaas, E.J. Root structure and functioning for efficient acquisition of phosphorus: Matching morphological and physiological traits. Ann. Bot. 2006, 98, 693-713. [CrossRef]

19. Hammer, E.C.; Balogh-Brunstad, Z.; Jakobsen, I.; Olsson, P.A.; Stipp, S.L.S.; Rillig, M.C. A mycorrhizal fungus grows on biochar and captures phosphorus from its surfaces. Soil Biol. Biochem. 2014, 77, 252-260. [CrossRef]

20. Solaiman, Z.M.; Blackwell, P.; Abbott, L.K.; Storer, P. Direct and residual effect of biochar application on mycorrhizal root colonisation, growth and nutrition of wheat. J. Soil Res. 2010, 48, 546-554. [CrossRef]

21. Vanek, S.J.; Lehmann, J. Phosphorus availability to beans via interactions between mycorrhizas and biochar. Plant Soil. 2015 [CrossRef]

22. Mickan, B.S.; Abbott, L.K.; Stefanova, K.; Solaiman, Z.M. Interactions between biochar and mycorrhizal fungi in a water-stressed agricultural soil. Mycorrhiza 2016. [CrossRef] [PubMed]

23. Warnock, D.D.; Lehmann, J.; Kuyper, T.W.; Rillig, M.C. Mycorrhizal responses to biochar in soil-Concepts and mechanisms. Plant Soil 2007, 300, 9-20. [CrossRef]

24. Turner, N.C. Imposing and maintaining soil water deficits in drought studies in pots. Plant Soil 2019. [CrossRef]

25. Giovannetti, M.; Mosse, B. An evaluation of techniques for measuring vesicular arbuscular mycorrhizal infection in roots. New Phytol. 1980, 84, 489-500.

26. Kwak, S.S.; Kim, S.K.; Lee, M.S.; Jung, K.H.; Park, I.H.; Liu, J.R. Acidic peroxidases from suspension-cultures of sweet potato. Phytochemistry 1995. [CrossRef]

27. Lüttge, U. Plant physiology. Encycl. Ecol. 1949, 24, 549-557. [CrossRef]

28. Wu, S.J.; Ren, Y.T.; Wu, C.X. Comparative study on measurement methods of pH value of grassland soil. Chin. J. Soil Sci. 2018, 49, 343-348.

29. Vance, E.D.; Brookes, P.C.; Jenkinson, D.S. An extraction method for measuring soil microbial biomass C. Soil Biol. Biochem. 1987. [CrossRef]

30. Gao, Y.L.; Chao, X.X.; Fu, G.N.; Jia, T.; Zhang, X.M. Available phosphorus in different soil types. 2011, 162-164. [CrossRef]

31. Zhang, D.; Zhang, C.; Tang, X.; Li, H.; Zhang, F.; Rengel, Z.; Whalley, W.R.; Davies, W.J.; Shen, J. Increased soil phosphorus availability induced by faba bean root exudation stimulates root growth and phosphorus uptake in neighbouring maize. New Phytol. 2016, 209, 823-831. [CrossRef]

32. Kra, S.; Green, D.M. Acid and alkaline phosphatase dynamics and their relationship to soil microclimate in a semiarid woodland Soil Biol. Biochem. 2000, 32, 179-188.

33. Ren, A.T.; Zhu, Y.; Chen, Y.L.; Ren, H.X.; Li, J.Y.; Kay Abbott, L.; Xiong, Y.C. Arbuscular mycorrhizal fungus alters root-sourced signal (abscisic acid) for better drought acclimation in Zea mays L. seedlings. Environ. Exp. Bot. 2019, 167, 103824. [CrossRef]

34. Zhu, Y.; Lv, G.C.; Chen, Y.L.; Gong, X.F.; Peng, Y.N.; Wang, Z.Y.; Ren, A.T.; Xiong, Y.C. Inoculation of arbuscular mycorrhizal fungi with plastic mulching in rainfed wheat: A promising farming strategy. Field Crops Res. 2017, 204, 229-241. [CrossRef]

35. Gholamhoseini, M.; Ghalavand, A.; Dolatabadian, A.; Jamshidi, E.; Khodaei-Joghan, A. Effects of arbuscular mycorrhizal inoculation on growth, yield, nutrient uptake and irrigation water productivity of sunflowers grown under drought stress. Agric. Water Manag. 2013, 117, 106-114. [CrossRef]

36. Smith, S.E.; Facelli, E.; Pope, S.; Smith, F.A. Plant performance in stressful environments: Interpreting new and established knowledge of the roles of arbuscular mycorrhizas. Plant Soil. 2010. [CrossRef] 
37. Doubková, P.; Vlasáková, E.; Sudová, R. Arbuscular mycorrhizal symbiosis alleviates drought stress imposed on Knautia arvensis plants in serpentine soil. Plant Soil. 2013. [CrossRef]

38. Jeffery, S.; Verheijen, F.G.A.; van der Velde, M.; Bastos, A.C. A quantitative review of the effects of biochar application to soils on crop productivity using meta-analysis. Agric. Ecosyst. Environ. 2011, 144, 175-187. [CrossRef]

39. Deng, Y.; Feng, G.; Chen, X.; Zou, C. Arbuscular mycorrhizal fungal colonization is considerable at optimal Olsen-P levels for maximized yields in an intensive wheat-maize cropping system. Field Crops Res. 2017, 209, 1-9. [CrossRef]

40. Mackay, J.E.; Cavagnaro, T.R.; Müller Stöver, D.S.; Macdonald, L.M.; Grønlund, M.; Jakobsen, I. A key role for arbuscular mycorrhiza in plant acquisition of P from sewage sludge recycled to soil. Soil Biol. Biochem. 2017, 115, 11-20. [CrossRef]

41. de Figueiredo, C.C.; Farias, W.M.; Coser, T.R.; Monteiro de Paula, A.; Sartori da Silva, M.R.; Paz-Ferreiro, J. Sewage sludge biochar alters root colonization of mycorrhizal fungi in a soil cultivated with corn. Eur. J. Soil Biol. 2019, 93, 103092. [CrossRef]

42. Koide, R.T.; Kabir, Z. Extraradical hyphae of the mycorrhizal fungus Glomus intraradices can hydrolyse organic phosphate. New Phytol. 2000. [CrossRef]

43. Adhikari, S.; Gascó, G.; Méndez, A.; Surapaneni, A.; Jegatheesan, V.; Shah, K.; Paz-Ferreiro, J. Influence of pyrolysis parameters on phosphorus fractions of biosolids derived biochar. Sci. Total Environ. 2019, 695, 133846. [CrossRef]

44. de Figueiredo, C.C.; Pinheiro, T.D.; de Oliveira, L.E.Z.; de Araujo, A.S.; Coser, T.R.; Paz-Ferreiro, J. Direct and residual effect of biochar derived from biosolids on soil phosphorus pools: A four-year field assessment. Sci. Total Environ. 2020, 739, 140013. [CrossRef]

45. Berta, G.; Sampo, S.; Gamalero, E.; Massa, N.; Lemanceau, P. Suppression of Rhizoctonia root-rot of tomato by Glomus mossae BEG12 and Pseudomonas fluorescens A6RI is associated with their effect on the pathogen growth and on the root morphogenesis. Eur. J. Plant Pathol. 2005, 111, 279-288. [CrossRef]

46. Bi, Y.; Zhang, J.; Song, Z.; Wang, Z.; Qiu, L.; Hu, J.; Gong, Y. Arbuscular mycorrhizal fungi alleviate root damage stress induced by simulated coal mining subsidence ground fissures. Sci. Total Environ. 2019, 652, 398-405. [CrossRef] [PubMed]

47. Maherali, H. Is there an association between root architecture and mycorrhizal growth response? New Phytol. 2014, 204, 192-200. [CrossRef]

48. Zhang, J.; Zhang, Z.; Shen, G.; Wang, R.; Gao, L.; Kong, F.; Zhang, J. Growth performance, nutrient absorption of tobacco and soil fertility after straw biochar application. Int. J. Agric. Biol. 2016. [CrossRef]

49. McKay Fletcher, D.M.; Ruiz, S.; Dias, T.; Petroselli, C.; Roose, T. Linking root structure to functionality: The impact of root system architecture on citrate-enhanced phosphate uptake. New Phytol. 2020. [CrossRef] [PubMed]

50. Honvault, N.; Houben, D.; Nobile, C.; Firmin, S.; Lambers, H.; Faucon, M.P. Tradeoffs among phosphorus-acquisition root traits of crop species for agroecological intensification. Plant Soil 2020. [CrossRef]

51. Li, S.; Wang, S.; Fan, M.; Wu, Y.; Shangguan, Z. Interactions between biochar and nitrogen impact soil carbon mineralization and the microbial community. Soil Tillage Res. 2020, 196, 104437. [CrossRef] 